\title{
A Compact Wide band Printed LPDA Antenna for WLAN Applications in $5 \mathrm{GHz}$ Band
}

\author{
Shailendra Singh Pawar \\ Department of Electronics and Communication \\ Engineering, Maulana Azad National Institute of \\ Technology, Bhopal, India
}

\author{
Madhu Shandilya \\ Department of Electronics and Communication \\ Engineering, Maulana Azad National Institute of \\ Technology, Bhopal, India
}

\begin{abstract}
A compact wide band Printed LPDA (Log Periodic Dipole Array) antenna is proposed for WLAN applications in 5-6 $\mathrm{GHz}$ range. The antenna having dimensions of $36.58 \mathrm{~mm} \mathrm{x}$ $24.37 \mathrm{~mm} \times 1.6 \mathrm{~mm}$ is designed and simulated using HFSS 13 . The prototype of proposed antenna is developed using simple FR4 substrate. The proposed antenna works well in the desired operating bandwidth from $5-6 \mathrm{GHz}$ and covers dual bands of IEEE 802.11a $\quad(5.15-5.35 \mathrm{GHz}$ and 5.725$5.825 \mathrm{GHz}$ ) with VSWR effectively less than 2 . The antenna shows a wide impedance bandwidth of $1.643 \mathrm{GHz}$ from 4.869 $\mathrm{GHz}-6.512 \mathrm{GHz}$, with bandwidth efficiency of $28.87 \%$. The antenna gain is $>6 \mathrm{~dB}$ throughout the operating band, with max gain of $7.6 \mathrm{~dB}$ at $5.6 \mathrm{GHz}$ and stable radiation pattern in end fire direction. Measured results for $S_{11}$ parameter are in good agreement with simulated one, which validates the proposed antenna design.
\end{abstract}

\section{Keywords}

PLPDA (Printed Log Periodic Dipole Array), WLAN, FR-4, Wide band

\section{INTRODUCTION}

Nowadays WLAN applications are very popular with IEEE standards working in $2.4 \mathrm{GHz}$ and $5 \mathrm{GHz}$ band. IEEE 802.11a operating at $5 \mathrm{GHz}$ band $(5.15-5.35 \mathrm{GHz}$ and 5.725-5.825 GHz) facilitates relatively higher data rate than the $802.11 \mathrm{~b} / \mathrm{g}$ which operates at $2.4 \mathrm{GHz}$ band. So the design of a printed LPDA antenna operates over this band is presented in this work. The evolution of conventional antenna design has started from 1960, when Isbell [1] first introduces the traditional LPDA antenna in free space [1][6].The concept of conventional LPDA antenna is then applied to develop printed LPDA antenna [7]-[10].

There is a lot of work reported regarding the WLAN antenna design in $5 \mathrm{GHz}$ band using printed technology [11]-[18]. In [11] a wideband /dual band packaged antenna is proposed for WLAN applications in $5 \mathrm{GHz}$ band, using FR4 substrate. In spite of having facility of using as a wide band or as a dual band antenna, the peak gain obtained was very low (1.8 dbi at $5.25 \mathrm{GHz})$. In [12] a wide band patch antenna for $2.4 / 5 \mathrm{GHz}$ WLAN applications is designed using simple probe feed and air gap (capacitive gap) to improve the bandwidth. Reference [13] presents a compact and simple design of a CPW (Co-Planar Waveguide) fed planar antenna for UWB applications with dual band notch at $3.5 / 5.5 \mathrm{GHz}$. In [14] a stacked triangular dielectric resonator antenna (DRA) fed by a conformal patch is proposed for WLAN applications in the frequency range of 4 - $6.02 \mathrm{GHz}$. To improve the gain, BW and radiation performances of DRA, triangular shaped resonators with same dielectric constant and different sizes are stacked together. In [15] a compact triple band microstrip slot antenna applied to WLAN /WiMax applications is proposed. In spite of its simpler structure, peak gain achieved was low (4.32 dbi at $5.5 \mathrm{GHz})$. In [16] a compact printed planar UWB (Ultra Wide Band) antenna with dual band notched is proposed. Two rectangular parasitic strips are placed below the substrate to achieve dual band notched characteristic at 3.3-3.8 and 5.1-5.6 GHz bands. Reference [17], presents a simple $2.45 / 3.5 / 5.8 \mathrm{GHz}$ triple band circularly polarized printed monopole antenna with enhanced bandwidth. In [18] a compact dual band polarized LPDA with dimensions of $160 \times 160 \times 60 \mathrm{~mm}$ for MIMO WLAN applications is proposed. The proposed array exhibits the characteristics of high isolation and, good F/B ratios and average gain of 5 and 6 dbi over 2.4 and $5 \mathrm{GHz}$ band respectively.

This paper presents a simple design of a compact printed LPDA antenna for WLAN applications in $5 \mathrm{GHz}$ band. The antenna is designed using Carrels theory and then optimized using HFSS 13, a high frequency structure simulator based on FEM (Finite Element Method). The antenna is simulated on a simple FR4 epoxy substrate with dielectric constant of 4.4 and thickness of $1.6 \mathrm{~mm}$. The various design parameters like return loss, working bandwidth, radiation pattern and overall gain are used as indicators in the evaluation of performance enhancement. The proposed antenna works well in the desired frequency range with good return loss curve and satisfactory radiation pattern in end fire direction and maximum gain of $7.6 \mathrm{dbi}$ at $5.6 \mathrm{GHz}$.

\section{ANTENNA DESIGN}

The structure is very close to a standard (wire) LPDA and therefore the standard strategy to design an LPDA can be used [2], along with some modifications (Fig. 1).The property of antenna is mainly determined by 3 parameters the scale factor $\tau$, spacing factor $\sigma$ and number of diploes N. To achieve better radiation property, low return loss and high gain, we decide $\tau$ $=0.9$ and $\sigma=0.15$. All the adjacent dipoles elements are printed on two sides of micro strip substrate in an alternate way and are fed with coaxial cable at lower end using SMA connector. All the elements of antenna are fed by a paired strip to match the resistance of $50 \Omega$. For calculating the width of parallel strip feed line to match the required impedance of $50 \Omega$, a $25 \Omega$ standard micro strip with width of $\mathrm{h} / 2$ is designed using calculations given in [19] and optimized through HFSS 13.The resulting width of parallel strip obtained ; W=4.185 mm. Then effective dielectric constant is calculated by using relation;

$$
\varepsilon_{e f f}=\frac{\varepsilon_{r}+1}{2}+\frac{\varepsilon_{r}-1}{2}\left(1+\frac{10 h}{W}\right)^{-1 / 2}
$$


Now, starting with required bandwidth of 5-6 GHz, and following the rules given in [20], first the length of largest dipole $L_{\max }$ is determined as:

$$
L_{\max }=K_{1} \lambda_{\max }
$$

Where $\lambda_{\max }$ is the largest effective wavelength at the lowest operating frequency $5 \mathrm{GHz}$. $K_{1}$ is a constant depends on Scaling factor $\tau$ [20].Then length of shortest dipole element can be calculated by using equation;

$$
L_{\text {min }}=K_{2} \lambda_{\text {min }}
$$

Where $\lambda_{\min }$ is the shortest effective wavelength at highest operating frequency $6 \mathrm{GHz}$ and $K_{2}$ is lower truncation constant calculated using formula given in [20]. Now to cover the desired frequency range from 5-6 GHz, number of dipoles required are calculated as $\mathrm{N}=8.33 \approx 8$ from equation;

$$
N=1+\frac{\log \left(K_{2} / K_{1}\right)+\log \left(f_{l} / f_{u}\right)}{\log \tau}
$$

Where $f_{l}$ is lowest operating frequency $=5 \mathrm{GHz}$ and $f_{u}$ is highest operating frequency $=6 \mathrm{GHz}$. From equation (2) length of largest dipole element $\quad L_{\max }=16.943 \mathrm{~mm}$. Then width $\mathrm{W}_{1}$ of largest dipole can be determined by using the expression of characteristic impedance $Z_{0}$ of cylindrical dipole [2] by using equation;

$$
Z_{0}=\frac{\eta_{0}}{\pi}\left[\ln \left(\frac{L_{n}}{a_{n}}\right)-2.25\right]
$$

Where $a_{n}=$ radius of dipole, and $L_{n}$ its half length. Now width of largest dipole is calculated as in [21] by using formula;

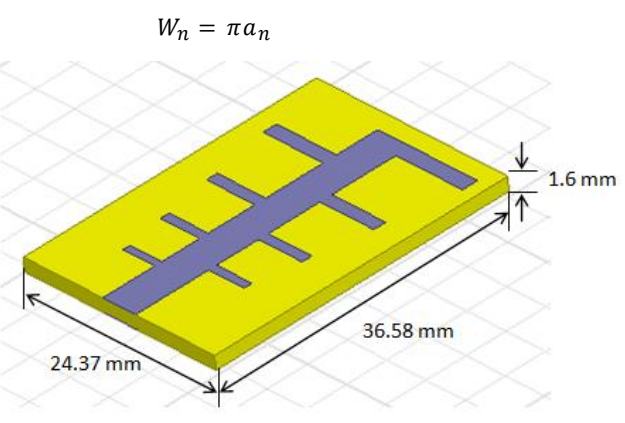

(a)

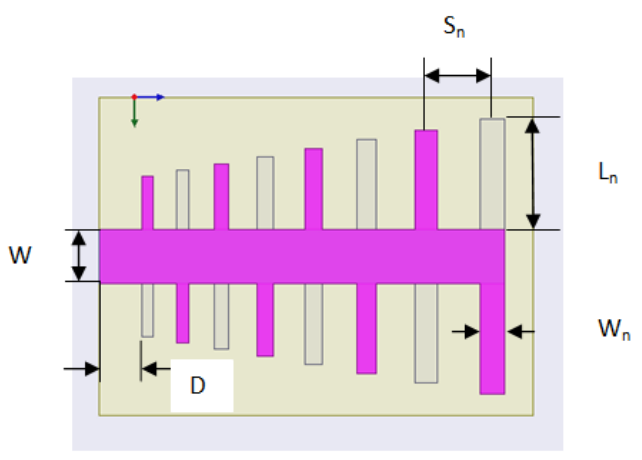

(b)

Fig. 1. Schematic layout of Printed LPDA antenna (a) Outer dimensions (b)Inner dimensions (Solid lines for front face while blanked lines for back face of the substrate) to match the impedance of $50 \Omega$. The length and width of other dipoles can be calculated by using well known expressions of LPDA;

$$
\begin{aligned}
& \frac{L_{n}+1}{L_{n}}=\frac{1}{\tau} \\
& \frac{W_{n}+1}{W_{n}}=\frac{1}{\tau}
\end{aligned}
$$

The spacing between two elements is also depends on the scaling factor $\tau$, as given in eq. (9)

$$
\frac{S_{n}+1}{S_{n}}=\frac{1}{\tau}
$$

Key design parameters and geometry of antenna are listed in Table 1 and Table 2 respectively.

\section{SIMULATION AND MEASURED RESULTS}

The PLPDA antenna designed in previous section then simulated and optimized using HFSS 13 to obtain various key parameters like return loss, gain and radiation pattern. Antenna is differentially fed at lower end using lumped port

Table 1. Key Design Parameters

\begin{tabular}{|c|c|}
\hline Parameters & Value \\
\hline Width of parallel strip line $(\mathrm{W})$ & $4.185 \mathrm{~mm}$ \\
\hline Feed length $(\mathrm{D})$ & $6.5 \mathrm{~mm}$ \\
\hline Scaling factor $(\tau)$ & 0.9 \\
\hline Spacing factor $(\sigma)$ & 0.15 \\
\hline Length of largest dipole $\left(L_{\max }\right)$ & $16.943 \mathrm{~mm}$ \\
\hline Effective dielectric constant $\left(\varepsilon_{e f f}\right)$ & 3.6962 \\
\hline
\end{tabular}

Table 2. Geometry of designed PLPDA

\begin{tabular}{|c|c|c|c|}
\hline Dipole & $\boldsymbol{L n}[\mathbf{m m}]$ & $\boldsymbol{W n}[\mathbf{m m}]$ & $\boldsymbol{S n}[\mathbf{m m}]$ \\
\hline 1 & 4.05 & 0.88 & - \\
\hline 2 & 4.501 & 0.98 & 2.70 \\
\hline 3 & 5.002 & 1.09 & 3.00 \\
\hline 4 & 5.557 & 1.21 & 3.33 \\
\hline 5 & 6.175 & 1.34 & 3.70 \\
\hline 6 & 6.861 & 1.49 & 4.11 \\
\hline 7 & 7.623 & 1.66 & 4.57 \\
\hline 8 & 8.471 & 1.85 & 5.08 \\
\hline
\end{tabular}

for simulation purpose. The feed length of antenna (length from smallest dipole $=\mathrm{D}$ ) plays an important role in deciding better impedance matching and return loss curve, so the feed length of antenna is properly calculated and optimized to get best return loss curve and impedance matching. The whole antenna structure is then simulated for a feed length of 6.5 $\mathrm{mm}$. To check the validity of simulation, prototype of proposed antenna is developed on FR-4 Substrate (Fig. 2), and $\mathrm{S}_{11}$ parameter measurement is performed using Agilent N9923A Vector Network Analyzer. It is observed (Fig. 3) that antenna works effectively in the desired operating band, with satisfactory matching between simulated and measured 
results. The differences may be due to effect of SMA connector and mismatching tolerance. The measured results show that antenna covers a wide frequency range of 1.643 $\mathrm{GHz}$ from $4.869 \mathrm{GHz}-6.512 \mathrm{GHz}$, with bandwidth efficiency of $28.87 \%$, which effectively follow the IEEE 802.11a WLAN standard operating at $5 \mathrm{GHz}$ band (5.15-5.35 $\mathrm{GHz}$ and 5.725-5.825 GHz). Further, Fig. 4 shows the gain of the antenna remains positive $(>6 \mathrm{~dB})$ throughout the operating

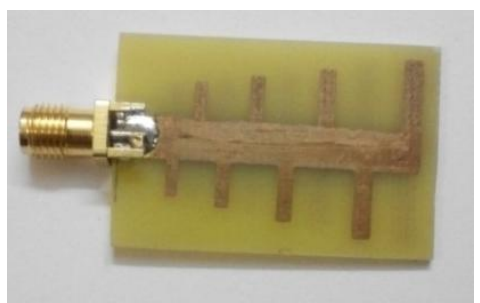

(a) Front side

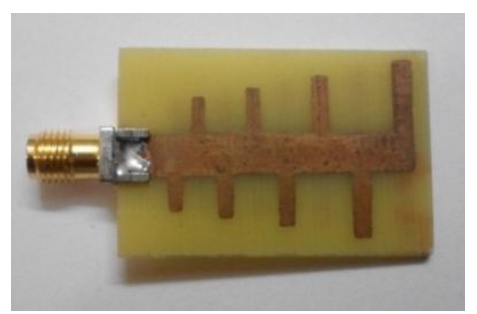

(b) Back side

Fig. 2. Hard ware of proposed antenna design (a), (b)

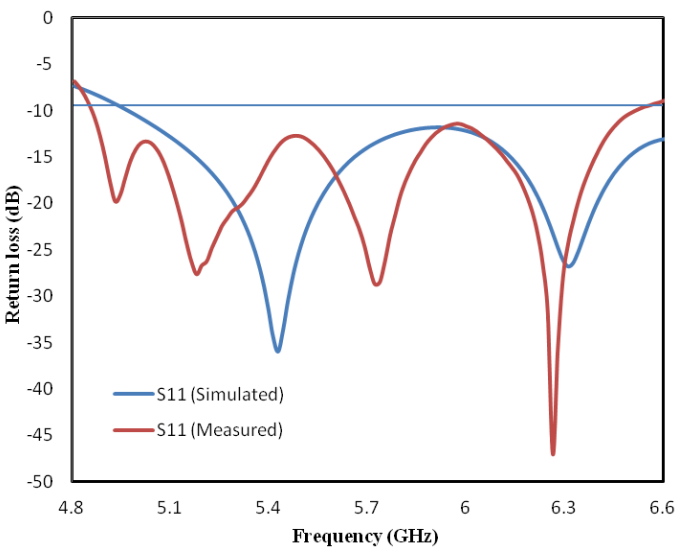

Fig. 3. Simulated $S_{11}$ vs frequency

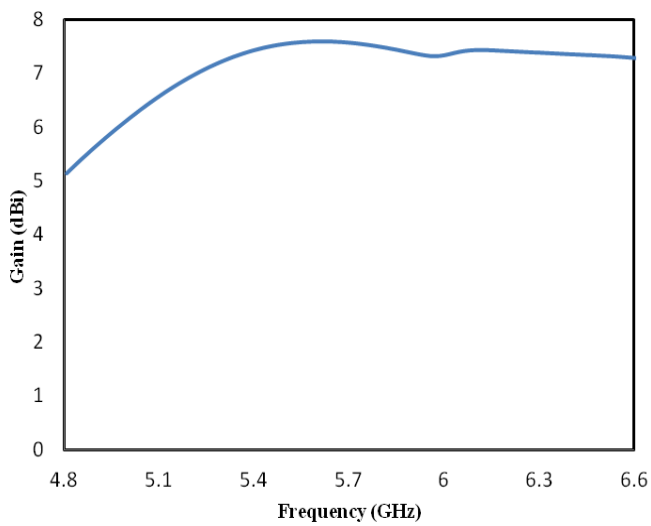

Fig. 4. Gain vs frequency band, with maximum gain of $7.6 \mathrm{~dB}$ at $5.6 \mathrm{GHz}$. Fig. 5,6 and 7 show $\mathrm{E}$ plane and $\mathrm{H}$ plane radiation pattern of the

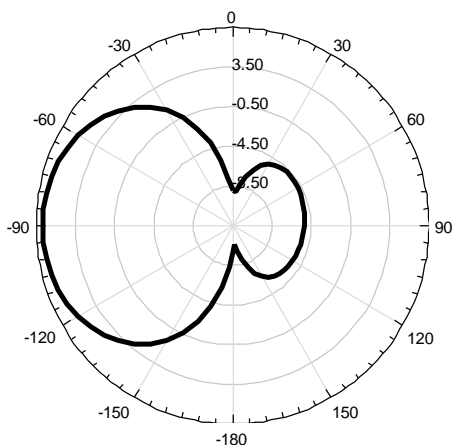

(a)

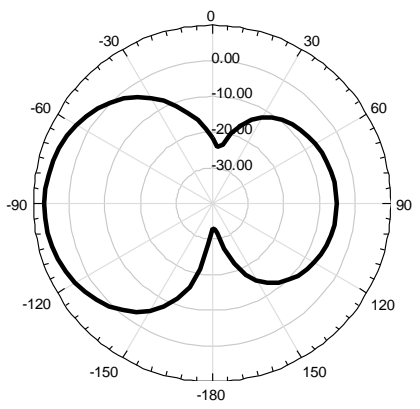

(b)

Fig. 5. Radiation pattern at $\mathbf{f}=5.1 \mathrm{GHz}$ (a) $\mathrm{E}$ plane (b) $\mathrm{H}$ plane

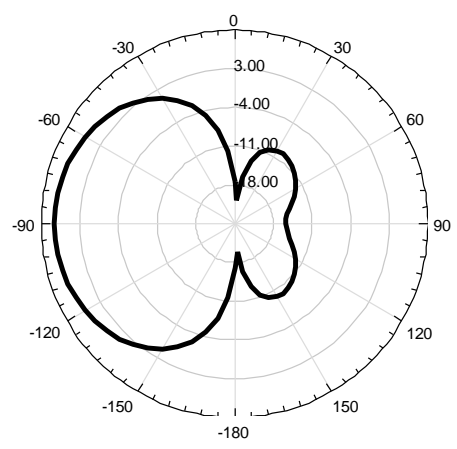

(a)

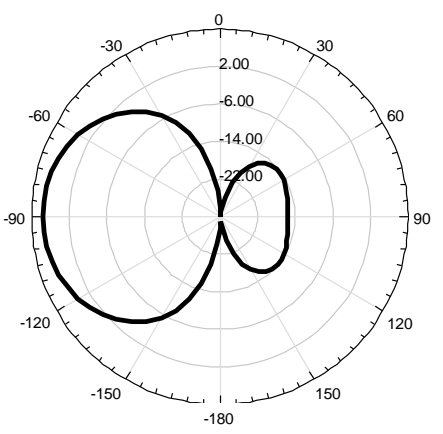

(b)

Fig. 6. Radiation pattern at $\mathrm{f}=5.5 \mathrm{GHz}$ (a) $\mathrm{E}$ plane (b) $\mathrm{H}$ plane 


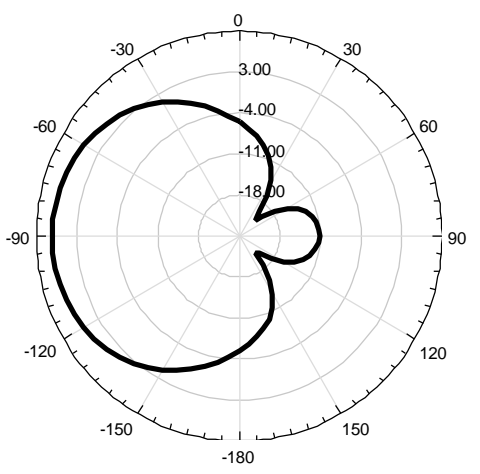

(a)

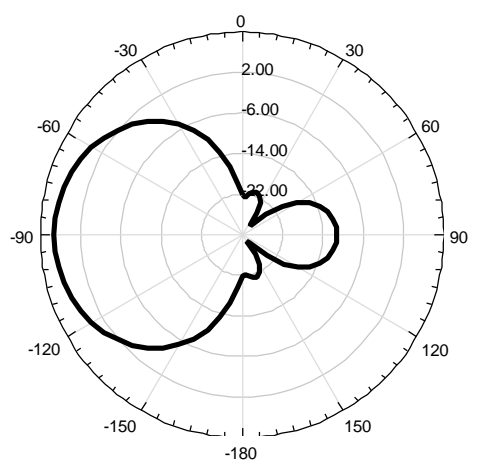

(b)

Fig. 7. Radiation pattern at $\mathrm{f}=6.3 \mathrm{GHz}$ (a) $\mathrm{E}$ plane (b) $\mathrm{H}$ plane

proposed antenna at $5.1 \mathrm{GHz}, 5.5 \mathrm{GHz}$ and $6.3 \mathrm{GHz}$ respectively. It shows an end fire behavior within the desired frequency band.

\section{CONCLUSION}

This paper analyzes the design procedure of a compact printed LPDA antenna for WLAN applications in $5 \mathrm{GHz}$ band. The $\mathrm{S}_{11}$ parameter shows good impedance bandwidth of 1.643 $\mathrm{GHz}$ from $4.869 \mathrm{GHz}-6.512 \mathrm{GHz}$, with bandwidth efficiency of $28.87 \%$. Also the gain of antenna is $>6 \mathrm{~dB}$ throughout the operating band, with maximum gain of $7.6 \mathrm{~dB}$ at 5.6 GHz. Antenna shows stable radiation pattern in end fire direction for whole operating band. The dimensions of antenna are $36.58 \mathrm{~mm} \times 24.37 \mathrm{~mm} \times 1.6 \mathrm{~mm}$, shows compactness of the structure. The measured result for $S_{11}$ parameter validates the proposed antenna design. Hence the proposed antenna is well suited in present scenario of wireless communication systems to compete the demand of wide bandwidth, high gain and stable radiation pattern. Further the size of antenna can be reduced by using fractal geometries like Koch and tree dipole structures in future. The main challenge is to achieve the same bandwidth and gain, while using these geometries.

\section{REFERENCES}

[1] D. Isbell, "Log Periodic Dipole Arrays," IRE Trans. Antennas Propag., (Mar. 1960) vol. 8, no. 3, 260-267.

[2] R. Carrel, "The Design of the Log-Periodic Dipole Antenna,” IRE Int. Conventional Rec., 1961, vol. 9, pt. Part 1, 61-75.
[3] J. Carr, "Some Variations in Log-Periodic Antenna Structures," IRE Trans. Antennas Propag., (Feb. 1961) vol. 9, no. 2, 229-230.

[4] R. Mittra and K. E. Jones, "Theoretical Brillouin Diagrams for Monopole and Dipole Arrays and Their Applications to Log-Periodic Antennas," IEEE Trans. Antennas Propag., (Mar. 1964) vol. AP-51, no. 3, 533540 .

[5] N. Barbano, "Waveguide-fed Log Periodic Antennas," IRE Trans. Antennas Propag., (Mar. 1968) vol. 16, no. 3, 357-358.

[6] J. Wolter, "Solution of Maxwell's Equations for LogPeriodic Dipole Antennas," IEEE Trans. Antennas Propag., (Jun. 1970) vol. AP-18, no. 6, 734-741.

[7] C. K. Campbell, I. Traboulay, M. S. Suuthers, and H. Kneve, "Design Of A Stripline Log-Periodic Dipole Antenna," IEEE Trans. Antennas Propag., (May 1977) vol. AP-25, no. 5, 718-721.

[8] P. Alakananda and G. Inderjeet, "An Analysis of Log Periodic Antenna With Printed Dipoles," IEEE Trans. Antennas Propag., (Feb. 1981) vol. AP-29, no.2, 114119

[9] P. R. Pantoja, A. R. Sapienza, and F. C. Medeiros, “A Microwave Printed Planar Log-Periodic Dipole Array Antenna," IEEE Trans. Antennas Propag., (Oct. 1987) vol. AP-35, no. 10, 1176-1178.

[10] Nikolay Galchenko, Sergey Vartanyan, "Development Of Electromagnetic Methods Of Printed Dipole Antenna Design" , International Conference on Mathematical Methods in Electromagnetic Theory - MMET '98, 1998, vol.2, $562-564$.

[11] Ali, M. Sittironnarit, T. ; Hwang, H.-S. ; Sadler, R.A. ; Hayes, G.J., "Wide-band/dual-band packaged antenna for 5-6 GHz WLAN application" Antennas and Propagation, IEEE Transactions on , 2004, vol.52 , 610615.

[12] Ki Suk Yoon; Sung Min Kim; Woon Geun Yang, “ A novel Wideband Patch antenna for 2.4/5 Ghz WLAN applications" Asia Pacific Microwave Conference APMC, 2006, 2002 - 2005.

「13]Chu, Q.X.; Yang, Y.-Y., "3.5/5.5 Ghz dual band-notch ultra-wideband antenna" IET Electronics Letters, 2008, vol.44, 172-174.

[14] Kumari, R. ; Parmar, K. ; Behera, S.K., "Conformal patch fed stacked triangular dielectric resonator antenna for WLAN applications", International Conference on Emerging Trends in Robotics and Communication Technologies (INTERACT), (Dec 2010),104-107.

[15] Lin Dang; Zhen Ya Lei; Yong Jun Xie; Gao Li Ning; Jun Fan, "A Compact Microstrip Slot Triple-Band Antenna for WLAN/WiMAX Applications" Antennas and Wireless Propagation Letters, IEEE, 2010, vol. 9, 1178 1181 ,

[16] Azim, R.; Islam, M.T.; Mobashsher, A.T.; Misran, N.; Yatim, B. "Compact printed ultra-wideband antenna with dual band- notch characteristics", 14th International Conference on Computer and Information Technology (ICCIT), 2011, $117-121$. 
[17] The Viet Hoang; Hyun Chang Park, "Very simple 2.45/3.5/5.8 GHz triple-band circularly polarized printed monopole antenna with bandwidth enhancement", IET Electronics Letters, 2014, vol. 50, Issue: 24, 1792-1793.

[18] Rama S.R.,Vakula D.,Sarma N.V.S.N., "Multiband multipolarized planar antenna for WLAN/WiMAX applications", 31st International Review of Progress in Applied Computational Electromagnetics (ACES), 2015, $1-2$.

[19] R. Garg, P. Bhartia, Inder Bahl, A. Ittipiboon, 2001 Microstrip Antenna Design Handbook. Artech House.
[20] Thomas A. Milligan, 2005 Modern Antenna Design. IEEE Press, A John Wiley \& Sons, Inc., Publication, Second Edition.

[21] Giovanni A. Casula, Paolo Maxia, Giuseppe Mazzarella, and Giorgio Montisci, "Design Of A Printed LogPeriodic Dipole Array For Ultra-Wideband Applications", Progress In Electromagnetics Research C, 2013, Vol. 38, 15-26. 